\title{
Comparison of Anaerobic Performance and Agility Characteristics Between American Football and Indoor Soccer Players
}

\author{
Sercan Öncen ${ }^{1}$, Levent Tanyeri ${ }^{2}$ \\ ${ }^{1}$ School of Physical Education and Sports, Tekirdağ Namık Kemal University, Tekirdağ, Turkey \\ ${ }^{2}$ School of Physical Education and Sports, Kafkas University, Kars, Turkey \\ Correspondence: Sercan Öncen, School of Physical Education and Sports, Tekirdağ Namık Kemal University, Tekirdağ, \\ Turkey.
}

Received: February 26, 2019

doi:10.11114/jets.v7i4.4103
Accepted: March 20, 2019 Online Published: March 21, 2019

URL: https://doi.org/10.11114/jets.v7i4.4103

\begin{abstract}
Anaerobic energy metabolism and agility are significant determinants of performance within the game actions of team sports such as Indoor Soccer (IS) and American Football (AF) where physical activities labeled as explosive power take place intensively (Beam \& Adam, 2011). In the study, the agility skills of male participants of Indoor soccer players (ISp; n10) and American Football players $\left(\mathrm{AF}_{\mathrm{P}} ; \mathrm{n} 10\right)$ have been measured by T-test, Illinois agility test and 505 agility tests and the anaerobic energy metabolism, anaerobic capacity (AC) and anaerobic power (AP) has been measured by Wingate anaerobic power test (WAnT) Monark E894 bicycle ergometer. According to the findings of agility and WAnT measurements, $\mathrm{IS}_{\mathrm{P}}$ has a significant superiority at $\mathrm{AP}$ evaluations although $\mathrm{AC}$ averages of two groups are similar $(\mathrm{p}<0,05) . \mathrm{IS}_{\mathrm{P}}$ have better scores than $\mathrm{AF}_{\mathrm{P}}$ at agility tests T-test $23.7 \%(\mathrm{p}<0,05)$, Illinois agility test $9.6 \%(\mathrm{p}<0,05), 505$ test $8.9 \%(\mathrm{p}>0,05) . \mathrm{AF}_{\mathrm{P}}$ has $9.2 \%$ more $\mathrm{BMI}$ averages than $\mathrm{IS}_{\mathrm{P}}$. Considering the negative effect of BMI on agility skill, this situation is thought to affect the agility skill of $\mathrm{AF}_{\mathrm{P}}$ negatively. WAnT measurements have enabled us to evaluate the lower extremity power output of the participants of $\mathrm{AF}_{\mathrm{P}}$ and $\mathrm{IS}_{\mathrm{P}}$. It has been recommended to determine the upper extremity power output in order to understand the differences and the anaerobic energy metabolism between two groups better.
\end{abstract}

Keywords: anaerobic power, agility, American football, indoor soccer

\section{Introducation}

While anaerobic power is expressed as "the ability of the individual to use the phosphagen system in short term high intensity muscle activities", anaerobic capacity is defined as the total amount of energy obtained from the combination of anaerobic glycolysis and phosphagen system (Medbo, et al., 1988; Rogers, 1990; Tabata, et al., 1996; Calvo, et al., 2002). Performing the activities difficult to practice qualitatively is directly proportionate to anaerobic power (AP) and anaerobic capacity (AC) should be high in order to repeat these activities successively and coordinately without fatigue (Katch \& Weltman, 1979; Maud \& Shultz, 1986). In case of the fact that body fat percentage is excessive and body mass without fat is insufficient, high fat rate may cause decrease in the capacity of agility at the same time (Heyward \& Stolarczyk 1996).

Agility is a significant component for many branches of sports (Getchell, 1979; Çakır, 2019). It is also a control and coordination skill which enables the body and the joints to be at the right position at space during rapid change of directions all along an activity streak (Sheppard \& Young, 2006). It can be defined as being able to change the direction of the body parallel or the other way round swiftly, flowingly and in a controlled manner in case of a high momentum. Meanwhile, "Agility is defined as the ability of stopping suddenly, changing direction and accelerate again. These components are important in several branches of sports such as American football, basketball, football, indoor soccer." (Reiman \& Manske, 2009). Sheppar has touched upon the importance of the sub classifications of the concept of agility by responding to the question "Which factors affect the agility performance?" as; "When the sub classifications of the concept of agility are not understood by sport scientists and trainers, it means that they cannot satisfy the needs of the players about agility" and they have identified the sub components that constitute the agility at the table of universal agility evaluation (Sheppard \& Young, 2006).

Indoor soccer is a type of game played in the field of 20 x $40 \mathrm{~m}$ with 1 goalkeeper and 4 players and which each team 
has no limits of player substitutions. The time stops when the ball is out of the game which is similar to the basketball. For this reason, it is seen that the duration of the game which is 40 minutes extends $75-85 \%$ (Pepe et al, 2010). IS includes high intensity activities (Barbero-Alvarez, et al, 2008; Castagna, et al, 2009) and there are several integrities of actions that require instant change of speed and direction within the competitive game (Ré, et al., 2010;).Since the size of the playing field and the ground is suitable for the acceleration of the game ball, it affects the flow of the game. The average running rate in Indoor Soccer consists of $13.7 \%$ high intensity sprints and $8.9 \%$ sub-maximal sprints. This shows that the players $\mathrm{HR}_{\text {res }}$ have a work load of $90 \%$ (Barbero-Alvarez, et al, 2008). An improved anaerobic power and a rapid recovery capacity for indoor soccer players will help them be successful in meeting the workload requested by the branch.

American Football team consists of 45 players whose positions and duties are different. There are different duties such as blocking, ball stealing, ball carrying, passing within the positions of defense and offence. The selection of the players to the positions is proportionate to their physical features to large extent. AF is based on adapting the instant variables in basic game principles in a short time. Agility trainings constitute an important portion of training programs in terms of adapting instant changes as far as possible (Young, et al., 2001; Hoffman, 2008; Nimphius, et al., 2013; Condello, et al., 2013).

Anaerobic power and agility features are significant determinants of performance for both branches of sports (Beam \& Adam, 2011). In this respect, it was aimed to better understand the anaerobic power and agility aspects of these two groups.

\section{Method}

\subsection{Subjects}

Indoor soccer players (IS $;$ n10) and American Football players $\left(\mathrm{AF}_{\mathrm{P}} ; \mathrm{n} 10\right)$ who are intercollegiate athletics have participated in the study. PARQ and ACSM risk factor analysis has been applied to the participants before the study and only the participants having no health risks have been included in the study.

\subsection{Experimental Procedure}

Tall stature, body weights and agility tests (photocell) have been measured. A 10-minute warm-up protocol has been implemented to the participants before the measurements. They have been given a full break at every measurement. The measurement of both groups has been carried out on the same ground with regards to the standardization of the measurements. Test procedures have been introduced before implementation for familiarization.

\subsection{Agility Tests Protocol}

In agility performance measurements of the participants, T-test including forward, lateral and backward running (Pauole, 2000,), 505 agility test including deceleration and acceleration at 180 degrees rotation (Draper, 1985), and Illinois agility test which tests the ability to turn in different directions and angles (Getchell, 1979) have been used.The participants have been requested to implement the test twice and their best score has been recorded. They have been given full break between these two trials.

\subsection{Wingate Anaerobic Perfomance Test (WAnT) Protocol}

In the study, Monark E894 bicycle ergometer has been used. WAnT is based on maximal pedaling on bicycle ergometer against previously determined stable load $(7.5 \% / 0.1-\mathrm{Kg})$ within six equal time periods once in every five seconds (Reiser, et al., 2002; Calbet, et al., 2003; Stone, et al., 2004) automatically in 30 seconds (Zupan, et al., 2009). In WAnT measurements, lover body-peak power (AP) obtained within any of the five second-period carried out during the test, anaerobic capacity (AC) showing the average workload performed during the test and the fatigue index (FI) that represents for the percentage of the decrease of performance have been received for consideration. The test procedure consists of 10 -second countdown phase at the participants' own speed, pedaling phase at maximum speed for 30 seconds and active recovery phase.

\subsection{Data Analysis}

Descriptive statistical analysis has been applied in the study and arithmetic average, standard deviation, maximum and minimum values of each variable in terms of measurement results have been estimated separately and normality distribution (Shapiro-wilk) assessments have been made. Independent two sample T-tests have been used for determining the difference between groups and the significance level has been taken as $\mathrm{p}<0,05$. 


\section{Results}

Table 1. Age, height, weight and BMI statistics of participants

\begin{tabular}{lccc}
\hline & & $\mathbf{I S}_{\mathbf{p}}(\mathbf{n}: \mathbf{1 0})$ & $\mathbf{A F}_{\mathbf{p}}(\mathbf{n : 1 0})$ \\
\hline Age $\quad($ years $)$ & $20 \pm 2$ & $22 \pm 2$ \\
Height $\quad(\mathbf{c m})$ & $176.7 \pm 5.5$ & $177 \pm 5.1$ \\
Weight $\quad(\mathbf{k g})$ & $68.9 \pm 6.7$ & $75.3 \pm 7.6$ \\
BMI & $22.02 \pm 1.24$ & $24.06 \pm 2.62$
\end{tabular}

Although $\mathrm{IS}_{\mathrm{P}}$ and $\mathrm{AF}_{\mathrm{P}}$ have similarities in view of age, height and body weight averages, $\mathrm{BMI}$ averages of $\mathrm{AF}_{\mathrm{P}}$ is $9.4 \%$ higher than IS $\mathrm{S}_{\mathrm{P}}(\mathrm{p}=.039 ; \mathrm{p}<0,05)$.

Table 2. Wingate anaerobic test (WAnT) assessment

\begin{tabular}{lcccccc}
\hline & & Mean & SD & Min & Max & P \\
\hline \multirow{2}{*}{ AP $\quad(\mathbf{W} / \mathbf{k g})$} & $\mathrm{IS}_{\mathrm{p}}$ & 9.88 & 1.464 & 8.05 & 12.33 & .008 \\
& $\mathrm{AF}_{\mathrm{p}}$ & 7.82 & 1.644 & 5.8 & 10.60 & \\
\multirow{2}{*}{$\mathbf{A C} \quad(\mathbf{W} / \mathbf{k g})$} & $\mathrm{IS}_{\mathrm{p}}$ & 6.17 & 0.762 & 4.79 & 7.17 & .134 \\
& $\mathrm{AF}_{\mathrm{p}}$ & 5.33 & 1.509 & 3.45 & 8.86 & \\
\multirow{2}{*}{ FI $(\boldsymbol{\%})$} & $\mathrm{IS}_{\mathrm{p}}$ & 71.54 & 7.106 & 57.03 & 81.99 & \multirow{2}{*}{078} \\
& $\mathrm{AF}_{\mathrm{p}}$ & 78.08 & 8.388 & 63.14 & 91.71 & \\
\hline
\end{tabular}

No significant difference has been found between the participant groups in view of fatigue index occurred during the test (FI; 71.5\% - 78.08\%) and anaerobic capacity (AC; $6.17 \pm 0.762 \mathrm{~W} / \mathrm{kg}-5.33 \pm 1.509 \mathrm{~W} / \mathrm{kg}$ ). However, at the highest power output measurements showed up at any period of time, $\mathrm{IS}_{\mathrm{P}}$ has significant difference in anaerobic power output (AP; $9.88 \pm 1.464 \mathrm{~W} / \mathrm{kg}-7.82 \pm 1.644 \mathrm{~W} / \mathrm{kg}$ ).

Table 3. Agility tests assessment

\begin{tabular}{lcccccc}
\hline & & Mean & SD & Min & Max & P \\
\hline \multirow{2}{*}{ T.Test (sec) } & $\mathrm{IS}_{\mathrm{p}}$ & 9.31 & 0.362 & 8.79 & 9.89 & .000 \\
& $\mathrm{AF}_{\mathrm{p}}$ & 11.52 & 1.172 & 9.98 & 8.79 & \\
IIllusion Agility Test (sec) & $\mathrm{IS}_{\mathrm{p}}$ & 15.41 & 0.498 & 14.69 & 16.43 & \\
& $\mathrm{AF}_{\mathrm{p}}$ & 16.90 & 0.974 & 15.94 & 18.82 & .001 \\
\multirow{5}{*}{$\mathbf{5 0 5}$ Agility Test (sec) } & $\mathrm{IS}_{\mathrm{p}}$ & 2.34 & 0.077 & 2.24 & 2.52 & \\
& $\mathrm{AF}_{\mathrm{p}}$ & 2.55 & 0.257 & 2.24 & 2.96 & .063 \\
\hline
\end{tabular}

$I_{\mathrm{P}}$ has a significant difference statistically in T-tests and Illinois agility tests including rotations of different directions and angles $(\mathrm{p}<0,05)$.On the contrary, there is no significant difference between $\mathrm{IS}_{\mathrm{P}}$ and $\mathrm{AF}_{\mathrm{P}}$ in 505 agility test which requires a deceleration from a high speed and maximum acceleration later again.

\section{Discussion}

Table 4.A comparison of literature on $\mathrm{AF}_{\mathrm{p}}$ and $\mathrm{IS}_{\mathrm{p}}$ participants scores

\begin{tabular}{lccccc}
\hline & $\begin{array}{c}\text { *NCAA Division III } \\
(\mathrm{sec})\end{array}$ & $\begin{array}{c}\text { *Elite High School } \\
\text { Football } \\
(\mathrm{sec})\end{array}$ & $\begin{array}{c}\text { Competitor College } \\
\text { Athletes } \\
(\mathrm{sec})\end{array}$ & $\begin{array}{c}\mathrm{IS}_{\mathrm{p}} \\
(\mathrm{sec})\end{array}$ & $\begin{array}{c}\mathrm{AF}_{\mathrm{p}} \\
(\mathrm{sec})\end{array}$ \\
\hline $\begin{array}{l}\text { Mean } \\
(\text { sec })\end{array}$ & 9.11 & 10.30 & 10.0 & 9.31 & 11.51 \\
\hline
\end{tabular}

*J.Hoffman, 2006, Norm for fitness, performance, and health (Champaign, IL, Human Kinetics)

When agility test evaluation of $\mathrm{AF}_{\mathrm{p}}$ in literature has been compared over T-test agility test with NCAA Division III (9.11 sec), Elite High School Football $(10.30 \mathrm{sec})$ and competitor college athletes $(10 \mathrm{sec}$.$) , it has been observed that it is$ lower as a feature of agility and it can be stated that $\mathrm{IS}_{\mathrm{P}}$ has approached the times of NCAA Division III.

There is a positive relationship between fat-free mass and physical performance. The increase in body fat rate can result 
in a negative effect in terms of physical performance. High rate of body fat and the increase in body mass may affect sportive performance negatively regarding both accelerating the body weight rapidly and increasing the energy cost (Heyward \& Stolarczyk, 1996; Boileau \& Horswill, 2002).

In the proportion between BMI body mass with fat and fat-free mass, the increase in fat will result in the decrease in power per $\mathrm{kg}$. For this reason, high $\mathrm{BMI}$ values of $\mathrm{AF}_{\mathrm{P}}$ results in the decrease in relative average power distribution per $\mathrm{kg}$. It has been considered that higher $\mathrm{BMI}$ values of $\mathrm{AF}_{\mathrm{P}}$ than $\mathrm{IS}_{\mathrm{P}}$ affect the agility performance negatively.

It is impossible to say that this feature of intercollegiate athletes who are tested for American football where high rate of agility skill in game actions has impact on positive performance is more developed in respect to IS $\mathrm{P}_{\mathrm{P}}$ Although there is a similarity between the two groups about the instant peak power output, $\mathrm{AF}_{\mathrm{P}}$ is significantly lower than $\mathrm{IS}_{\mathrm{P}}$ in terms of overcoming the total workload. According to this evaluation, it means that the increase in the number of changes in direction will result in decrease in the agility performance of $\mathrm{AF}_{\mathrm{P}}$. In addition, when we compare with the players of NCAA Division III College American Football which is similar in view of the categories of branch and age, it has been observed that it is low likewise. However, it is clear that the number of participants is needed to be increased and a table of comparison which compares the population with equivalent populations is necessary.

\section{References}

Barbero-Alvarez, J. C., Soto, V. M., Barbero-Alvarez, V., \& Granda-Vera, J. (2008). Match analysis and heart rate of futsal players during competition. Journal of sports sciences, 26(1), 63-73. https://doi.org/10.1080/02640410701287289

Beam, W. C., \& Adams, G. M. (2011). Exercise physiology laboratory manual (6.st ed). McGraw-Hill

Boileau, R. A., \& Horswill, C. A. (2002). Body composition in sports: Measurement and applications for weight loss and gain, "Exercise and sport science" (Ed. W.E, Garrett, D.T., Kirkendall)'de, Lippincott Williams and Wilkins, Philadelphia, USA., 319-338.

Çakır, E. (2019). Investigation of female soccer players performance values based on ambient temperature. Universal Journal of Educational Research, 7(1), 239-243, 2019

Calbet, J. A., De Paz, J. A., Garatachea, N., De Vaca, S. C., \& Chavarren, J. (2003). Anaerobic energy provision does not limit Wingate exercise performance in endurance-trainedcyclists. Journal of Applied Physiology, 94(2), 668-676. https://doi.org/10.1152/japplphysiol.00128.2002

Calvo, M., Rodas, G., Vallejo, M., Estruch, A., Arcas, A., Javierre, C., \& Ventura, J. (2002). Heritability of explosive power and anaerobic capacity in humans. European Journal of Applied Physiology, 86(3), 218-225. https://doi.org/10.1007/s004210100522

Castagna, C., D’Ottavio, S., Vera, J. G., \& Álvarez, J. C. B. (2009). Match demands of professional Futsal: a case study. Journal of Science and medicine in Sport, 12(4), 490-494. https://doi.org/10.1016/j.jsams.2008.02.001

Condello, G., Schultz, K., \& Tessitore, A. (2013). Assessment of sprint and change-of-direction performance in college football players. International journal of sports physiology and performance, 8(2), 211-212. https://doi.org/10.1123/ijspp.8.2.211

Draper, J. A., \& Lancaster, M. G. (1985). The 505 Test: A test for agility in the horizontal plane. Aust. J. Sci. Med. Sport. $17,15-18$

Getchell, B. (1979). Physical Fitness: 'A Way of Life', 2nd ed. New York: John Wiley and Sons, Inc.

Heyward, V. H., \& Stolarczyk, L. M. (1996). Applied body composition assessment. Champaign, IL; Human Kinetics, USA.

Hoffman, J. R. (2008). The applied physiology of American football. International Journal of Sports Physiology and Performance, 3(3), 387-392. https://doi.org/10.1123/ijspp.3.3.387

Katch, V. L., \& Arthur, W. (1979). Interrelationship between anaerobic power output, anaerobic capacity and aerobic power. Ergonomics, 22(3), 325-332. https://doi.org/10.1080/00140137908924616

Maud, P. J., \& Shultz, B. B. (1986). Gender comparisons in anaerobic power and anaerobic capacity tests. British journal of sports medicine, 20(2), 51-54. https://doi.org/10.1136/bjsm.20.2.51

Medbo, J. I., Mohn, A. C., Tabata, I., Bahr, R., Vaage, O., \& Sejersted, O. M. (1988). Anaerobic capacity determined by maximal accumulated $\mathrm{O} 2$ deficit. Journal of applied physiology, 64(1), 50-60.

https://doi.org/10.1152/jappl.1988.64.1.50

Nimphius, S., Geib, G., Spiteri, T., \& Carlisle, D. (2013). Change of direction” deficit measurement in Division I 
American football players. J Aust Strength Cond, 21(S2), 115-7.

Pauole, K., Madole, K., Garhammer, J., Lacourse, M., \& Rozenek, R. (2000). Reliability and validity of the t-test as a measure of agility, leg power, and leg speed in college-aged men and women. The Journal of Strength \& Conditioning Research, 31(4), 572-577.

Pepe, O., Günay, E., Çoksevim, B., Sucan, S., \& Polat, M. (2010). Determining some physical parameters of soccer and in door soccer players. Ovidius University Annals, Series Physical Education and Sport. Romania, 10(2), $189-191$.

Ré, A. H. N, Corrêa, U. C., \& Böhme, M. T. S. (2010). Anthropometric characteristıcs and motor skills in talent selection and development in indoor soccer. Perceptual and Motor Skills, 110(3), 916-930. https://doi.org/10.2466/pms.110.3.916-930

Reiser, R. E. II., Peterson, M. L., \& Broker, J. E. (2002). Influence of hiporientation on wingate power out put and cycling technique. The Journal of Strength \& Conditioning Research, 16(4), 556-560.

Reisman, M. P., \& Manske, R. C. (2009). Functional Testing in Human Performance, Human Kinetics, USA

Rogers, C. (1990). Exercise Physiology Labarotory Manuel. (1st ed.). United State of America: Wm. C Brown Publishers, 85-11.

Sheppard, J. M., \& Young, W. B. (2006). Agility literature review: Classifications, training and testing. Journal of Sports Sciences, 24(9), 919-932. https://doi.org/10.1080/02640410500457109

Stone, M. H., Sands, W. A., Carlock, J. O. N., Callan, S. A. M., Dickie, D. E. S., Daigle, K., \& Hartman, M. (2004). The importance of isometric maximum strength and peak rate-of-force development in sprint cycling. The Journal of Strength \& Conditioning Research, 18(4), 878-884.

Tabata, I., Nishimura, K., Kouzaki, M., Hirai, Y., Ogita, F., Miyachi, M., \& Yamamoto, K. (1996). Effects of moderate-intensity endurance and high-intensity intermittent training on anaerobic capacity and $\mathrm{VO} \sim 2 \sim \mathrm{m} \sim \mathrm{a} \sim$ x. Medicine and Science in Sports and Exercise, 28, 1327-1330. https://doi.org/10.1097/00005768-199610000-00018

Young, W. B., McDOWELL, M. H., \& Scarlett, B. J. (2001). Specificity of sprint and agility training methods. The Journal of Strength \& Conditioning Research, 15(3), 315-319.

Zupan, M. F., Arata, A. W., Dawson, L. H., Wile, A. L., Payn, T. L., \& Hannon, M. E. (2009). Wingate anaerobic test peak power and anaerobic capacity classifications for men and women intercollegiate athletes. The Journal of Streng \& Conditioning Research, 23(9), 2598-2604. https://doi.org/10.1519/JSC.0b013e3181b1b21b

\section{Copyrights}

Copyright for this article is retained by the author(s), with first publication rights granted to the journal.

This is an open-access article distributed under the terms and conditions of the Creative Commons Attribution license which permits unrestricted use, distribution, and reproduction in any medium, provided the original work is properly cited. 